\title{
Are light traps baited with kairomones effective in the capture of Lutzomyia longipalpis and Lutzomyia intermedia? An evaluation of synthetic human odor as an attractant for phlebotomine sand flies (Diptera: Psychodidae: Phlebotominae)
}

\author{
Andrey J Andrade ${ }^{+}$, Mateus R Andrade, Edelberto S Dias', Mara C Pinto², Álvaro E Eiras \\ Laboratório de Ecologia Química de Insetos Vetores, Departamento de Parasitologia, Instituto de Ciências Biológicas, Universidade \\ Federal de Minas Gerais, Av. Presidente Antônio Carlos 6627, 31270-901 Belo Horizonte, MG, Brasil 'Centro de Pesquisas René Rachou- \\ Fiocruz, Belo Horizonte, MG, Brasil 2Faculdade de Farmácia, Universidade Estadual Paulista, Araraquara, SP, Brasil
}

Phlebotomine sand flies are often captured with human bait and/or light traps, either with or without an animal bait. More recently, synthetic attractants have been used as bait in traps to improve the capture of phlebotomine sand flies as well as other insects of medical and veterinary importance. The aim of the present study was to evaluate the effects of the kairomone 1-octen-3-ol (octenol) and the synthetic human odor BG-Mesh Lure ${ }^{\mathrm{TM}}$ (BGML-lactic acid, caproic acid and ammonia) baited in modified CDC light traps on the capture of phlebotomine sand flies. The experiments followed the $5 \times 5$ Latin square design. Among the species caught, Lutzomyia intermedia apparently presented a dose-dependent response to octenol. The response obtained with the BGML, alone or in combination with octenol $(5 \mathrm{mg} / \mathrm{h})$, indicated some degree of attractiveness of these baits to different phlebotomine sand fly species. Octenol seems to be more attractive to $\mathrm{L}$. intermedia than to Lutzomyia longipalpis, while the BGML presented a higher success in capturing L. longipalpis. When the components of the BGML were used separately, there was no increase in catching the female of L. intermedia. Apparently, there was no synergistic effect between the octenol and the BGML. In conclusion, the octenol and the BGML were demonstrated to be possible baits to attract some phlebotomine sand fly species.

Key words: kairomones - octenol - BG-Mesh Lure ${ }^{\mathrm{TM}}$ - Lutzomyia intermedia - Lutzomyia longipalpis - CDC light trap

Haematophagous dipterans of the Nematocera and Brachycera suborders have been objects of study for a better understanding of the behavioral mechanisms used by insects to find their blood meal. This is usually elicited by chemical stimuli (semiochemicals) called kairomones that are often released by the vertebrate hosts (Gibson \& Torr 1999).

Among the more than 500 species of the subfamily Phlebotominae that are known in the Americas, over 400 belong to the genus Lutzomyia (Young \& Duncan 1994, Galati 2003). Lutzomyia longipalpis (Lutz and Neiva) and L. intermedia (Lutz and Neiva) play an important role in the transmission of leishmaniases (Forattini 1973, Lainson 1989, Lemos \& Lima 2005). Host-preference studies of Lutzomyia spp. frequently use animals, such as chicken, dogs, horses (Quinnell et al. 1992, Ximenes et al. 1999, Bongiorno et al. 2003), and occasionally humans as bait (Quinnell et al. 1992, Aguiar et al. 1996, Rebollar-Telez et al. 1999, Pinto et al. 2001). Laboratory assays (e.g., precipitin test) have been used for the identification of hosts that provide the blood meal for the phlebotomine sand flies (Christensen et al. 1982, Afonso et al. 2005).

Financial support: FAPEMIG, CNPq

+ Corresponding author: bioandrey@gmail.com

Received: 5 December 2007

Accepted: 9 June 2008
CDC light traps (Sudia \& Chamberlain 1962) and Shannon traps (Shannon 1939) have been used as tools for monitoring phlebotomine sand flies, thus eliminating the ethical problems associates with using human bait. However, some studies have shown that certain phlebotomine sand fly species are highly anthropophilic but rarely phototropic (Alexander et al. 1995, Travi et al. 1998), while other species seem to be more phototropic than antropophilic, such as Lutzomyia verrucarum Townsend (Davies et al. 1995). It is possible that these species are responsive to non-specific kairomones such as $\mathrm{CO}_{2}$ (Quinnell et al. 1992, Campbell-Lendrum et al. 1999a), and can be attracted by different species of hosts. $\mathrm{CO}_{2}$ is the main volatile kairomone released by vertebrates and it is used by most haematophagous insects to find their hosts (Eiras 2001). Knudsen et al. (1979) demonstrated for the first time the attractiveness of $\mathrm{CO}_{2}$ (released from dry ice) to phlebotomine sand flies. Light traps (LT) baited with $\mathrm{CO}_{2}$ enhanced the capture of phlebotomine sand flies in the field (Chaniots 1983), despite the fact that attraction to $\mathrm{CO}_{2}$ was not observed in the laboratory (Nigam \& Ward 1991).

The chemical 1-octen-3-ol (octenol) is an important kairomone used by zoophilic dipteran species of the families Muscidae, Tabanidae, Ceratopogonidae and Culicidae to seek their hosts (Kline at al. 1990, Gibson \& Torr 1999, Bernier et al. 2000, Eiras 2001). To date, there is no evidence supporting the trapping of phlebotomine sand flies with this kairomone. Lactic acid was the 
first kairomone identified from human skin (Acree et al. 1968), and its effect in attracting mosquitoes has been evaluated, especially in combination with $\mathrm{CO}_{2}$ (Kline et al. 1990, Eiras \& Jepson 1991), ammonia and some fatty acids (Geier et al. 1999). Ammonia was identified from vertebrate odors in the 1970s (Larson et al. 1979) and has been shown to be an effective attractant for mosquitoes (Geier et al. 1999) and tabanids (Hribar et al. 1992). The combination of ammonia and lactic acid provides a synergistic effect that enhances the behavioral response of female mosquitoes (Geier et al. 1999). Similarly, the combination of lactic acid, ammonia, and caproic acid was shown to be very attractive for Aedes aegypti Linnaeus in both laboratory (Bosch et al. 2000) and field studies (Kröeckel et al. 2006). However, there has been no study evaluating the usefulness of these kairomones as attractants for phlebotomine sand flies.

The present study aims to evaluate the attractiveness of kairomones (octenol, lactic acid, ammonia, and caproic acid) baited in LT for catching phlebotomine sand flies, specially $L$. longipalpis and $L$. intermedia.

\section{MATERIALS AND METHODS}

Study area - The experiments were carried out in Varzelândia, state of Minas Gerais (MG), Brazil. Varzelândia city has a population of 17,372 inhabitants and 303 notified cases of American tegumentary leishmaniasis (ATL) were reported in 2000. Out of these, 25 were from the district of Brejo do Mutambal (15'33'13"S $44^{\circ} 00^{\prime} 18^{\prime \prime} \mathrm{W}$ ), where ATL is known to be endemic (Nunes et al. 2006, Andrade et al. 2007, Dias et al. 2007). All dwellings in Brejo do Mutambal have backyards with domestic animals, such as chickens, dogs, and horses. The district is surrounded by calcareous rocks, which extend into the backyards.

Kairomones - Octenol (98\% purity, density of $0.83 \mathrm{mg} /$ $\mathrm{ml}$, Aldrich Chemical Company) was dispensed according to Van Essen et al. (1994) at release rates of $4.6 \pm$ $0.30 ; 13.0 \pm 1.80$ and $22.7 \pm 3.30 \mathrm{mg} / \mathrm{h}$. The release rate of $0.5 \mathrm{mg} / \mathrm{h}$ was achieved using a polymer dispenser (AgriSense-BCS, Cardiff, UK). Lactic acid, caproic acid, and ammonia were released as a unique formulation called BG-Mesh Lure ${ }^{\mathrm{TM}}$ (Biogents GmHb, Germany) or individually through silicon tubing, a PVC tube, and a calcium carbonate block, respectively (Fig. 1). $\mathrm{CO}_{2}$ was not used as bait because of the limitations of the experimental area for handling and transportation, and the high cost of the delivery system. The use of $\mathrm{CO}_{2}$ was also avoided due to its lack of specificity, as $\mathrm{CO}_{2}$ is known to attract most phlebotomine sand fly species (Chaniots 1983, Cameron et al. 1991, Pinto et al. 2001, Beavers et al. 2004).

Experiments - The experiments were carried out during April and May 2005, when phlebotomine sand flies are considerably more abundant in the study area (Dias et al. 2007). Modified CDC LT (Pugedo et al. 2005) were installed $1.5 \mathrm{~m}$ above the ground level and kept in the field during five consecutive nights in a $5 \times 5$ Latin square design. The traps were installed at 18:00 h and removed at $08: 00 \mathrm{~h}$ of the next day. Captured phlebotomine sand flies were maintained in glass vials con-

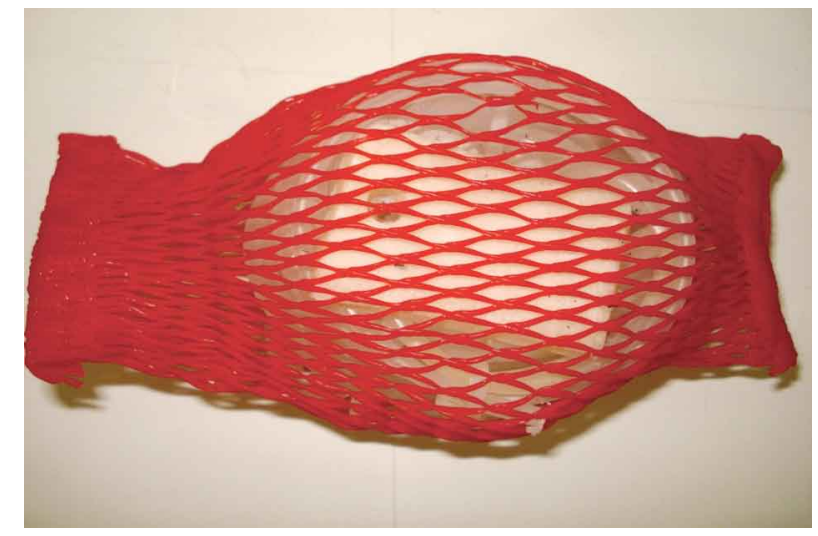

Fig. 1: BG Mesh Lure ${ }^{\mathrm{TM}}$ (BGML).

taining $70 \%$ alcohol and later taken to the laboratory for slide preparation using Canada balsam for males and Berlese liquid for females. The identification of species was based on Young and Duncan (1994).

Comparison of octenol release rates and site of capture (experiment 1) - A total of 25 traps per night was installed over five nights while alternating between the house areas and the woodlands. The octenol release rates of $0.5,4.6 \pm 0.30,13.0 \pm 1.80$ and $22.7 \pm 3.30$ will be referred to here as $0.5,5,15$, and $25 \mathrm{mg} / \mathrm{h}$, respectively. Octenol dispensers were individually baited on the outside of the PVC body of the modified CDC, between the fan and the screen. No octenol was used in the control trap. The traps were placed in woodland areas and the peridomiciliary environment.

Evaluation of phlebotomine sand flies' response to BGML kairomone formulation baited in LT with or without octenol (experiment 2) - The BGML formulation was evaluated using two dispensers: (i) an open BGML dispenser, which was a transparent plastic bowl of $7 \mathrm{~cm}$ (height) x $11.5 \mathrm{~cm}$ (diameter); and (ii) a semiopen BGML dispenser that consisted of the same plastic bowl with an opening of $2 \mathrm{~cm}$ of diameter. They were separately evaluated and associated with octenol release rates that captured the highest number of phlebotomine sand flies in experiment 1 . Octenol and dispensers were placed on the outside of the modified CDC LT as described in experiment 1 . For this experiment the LT were placed only in the peridomiciliary environment.

Evaluation of phlebotomine sand fly responses to complete BGML and to individual kairomones (experiment 3) - Each component of the BGML was evaluated individually in LT using the open or semi-open BGML dispensers, based on the previous experiment. The dispensers were placed as described previously. The treatment baits were: control (no attractant), lactic acid, caproic acid, ammonia, and BGML. Traps were also installed in the peridomiciliary environment.

Statistic analyses - The number of phlebotomine sand flies captured in each sample was transformed to the modified geometric mean (Williams 1937). Differences among phlebotomine sand fly captures were analyzed according 
to environment, gender and traps using non-parametric tests, Mann-Whitney and Kruskal-Wallis. Minitab ${ }^{\mathrm{TM}}$ Version 14 for Windows was used for analyses.

\section{RESULTS}

A total of 5,061 phlebotomine sand flies of 21 Lutzomyia species was captured during the present study. The most abundant species were L. intermedia and L. longipalpis, with 1,470 and 1,085 individuals, respectively. Lutzomyia renei (Martins, Falcão and Silva), Lutzomyia ischnacanta Martins, Souza and Falcão, Lutzomyia cavernicola (Costa Lima), and L. longipalpis, were captured in LT with or without baits and in all experiments. The Table shows the number of L. intermedia and L. longipalpis captured by the LT in experiments 1,2, and 3 .

Comparison of octenol release rates and the site of capture - A total of 3,889 phlebotomine sand flies were captured. The traps set in the woodland area $(2,377)$ captured a greater number compared to the traps set in the peridomiciliary environment $(1,512)$ (Mann-Whitney, $\mathrm{p}<0.001)$. In the peridomiciliary area, LT baited with $5 \mathrm{mg} / \mathrm{h}$ and $15 \mathrm{mg} / \mathrm{h}$ of octenol caught slightly higher numbers of phlebotomine sand flies than at other release rates. In the woodland area, traps baited with $25 \mathrm{mg} / \mathrm{h}$ of octenol caught a similar number of phlebotomine sand flies as compared with $5 \mathrm{mg} / \mathrm{h}$. The octenol release rates did not catch phlebotomine sand flies at significantly higher rates than the control traps (Kruskal Wallis, $\mathrm{p}=0.576)$ (Fig. 2). The most abundant phlebotomine sand fly species captured was $L$. intermedia, with 1,249 individuals, of which 359 were caught in the peridomiciliary area and 890 in woodland (Mann-Whitney, $\mathrm{p}<0.001$ ). The LT baited with $5 \mathrm{mg} / \mathrm{h}$ octenol captured $828(66 \%)$ females and 432 (24\%) males of sand flies. The highest number of L. intermedia caught was observed at $15 \mathrm{mg} / \mathrm{h}$ octenol, but no significant difference was detected among the release rates for males (Kruskal-Wallis, $\mathrm{p}=0.755$ ) or females (Kruskal-Wallis, $\mathrm{p}=0.383$ ) (Fig. 3). All octenol-baited traps captured lower numbers of $L$. longipalpis than the control traps, and a decrease of response

TABLE

Number of L. intermedia and L. longipalpis captured in the light traps, with or without baites, in Brejo do Mutambal, Varzelândia, state Minas Gerais, Brazil

\begin{tabular}{|c|c|c|c|c|}
\hline \multirow[b]{2}{*}{ Experiments (Month) } & \multirow[b]{2}{*}{ Kairomones } & \multirow[b]{2}{*}{ Sex } & \multicolumn{2}{|c|}{ Number of specimens } \\
\hline & & & L. intermedia & L. longipalpis \\
\hline \multirow[t]{10}{*}{1 (April 2005) } & 0 (Control) & $\widehat{0}$ & 68 & 110 \\
\hline & & q & 149 & 35 \\
\hline & Octenol $0.5(\mathrm{mg} / \mathrm{h})$ & $\widehat{0}$ & 58 & 86 \\
\hline & & q & 157 & 22 \\
\hline & Octenol 5 (mg/h) & $\hat{\sigma}$ & 58 & 121 \\
\hline & & q & 151 & 32 \\
\hline & Octenol 15 (mg/h) & $\hat{\sigma}$ & 98 & 83 \\
\hline & & q & 163 & 30 \\
\hline & Octenol 25 (mg/h) & $\hat{\sigma}$ & 145 & 63 \\
\hline & & q & 202 & 28 \\
\hline \multirow[t]{10}{*}{2 (May 2005) } & Control & $\hat{0}$ & 22 & 15 \\
\hline & & q & 8 & 8 \\
\hline & Bait $1^{a}$ & $\sigma^{\pi}$ & 27 & 21 \\
\hline & & 우 & 6 & 16 \\
\hline & Bait $2^{b}$ & $\sigma^{2}$ & 33 & 19 \\
\hline & & q & 15 & 15 \\
\hline & Bait $3^{c}$ & $\hat{\sigma}$ & 20 & 23 \\
\hline & & q & 10 & 12 \\
\hline & Bait $4^{d}$ & $\hat{\sigma}$ & 19 & 33 \\
\hline & & q & 9 & 5 \\
\hline \multirow[t]{10}{*}{3 (May 2005) } & Control & $\hat{0}$ & 8 & 107 \\
\hline & & q & 3 & 17 \\
\hline & Lactic acid & $\hat{0}$ & 5 & 50 \\
\hline & & q & 6 & 9 \\
\hline & Caproic acid & $\hat{\sigma}$ & 5 & 23 \\
\hline & & q & 3 & 10 \\
\hline & Ammonia & $\hat{0}$ & 4 & 27 \\
\hline & & 운 & 3 & 14 \\
\hline & BGML & $\hat{0}$ & 5 & 37 \\
\hline & & q & 10 & 14 \\
\hline
\end{tabular}

$a$ : BGML open dispenser; $b$ : BGML open dispenser + octenol 5mg/h; $c$ : BGML semi-open dispenser; $d$ : BGML semi-open dispenser + octenol $5 \mathrm{mg} / \mathrm{h}$. 


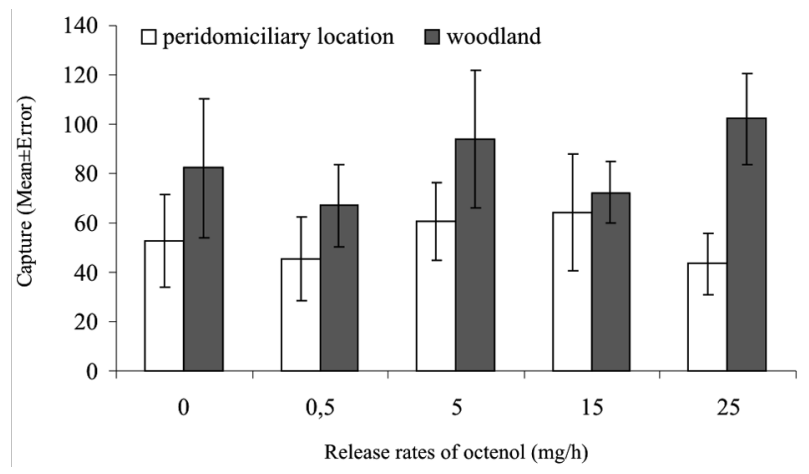

Fig. 2: arithmetic mean of sand flies captured in wood and peridomiciliary environment using light traps baited with different release rates of octenol (Brejo do Mutambal, MG-April 2005).

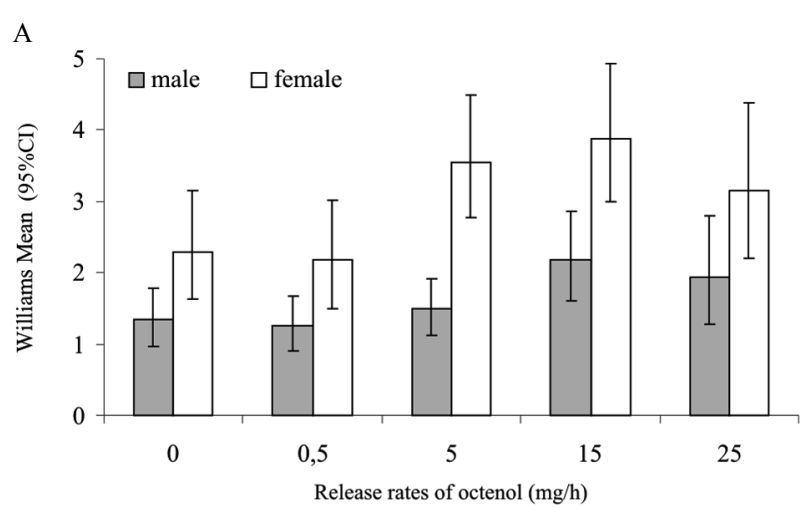

B

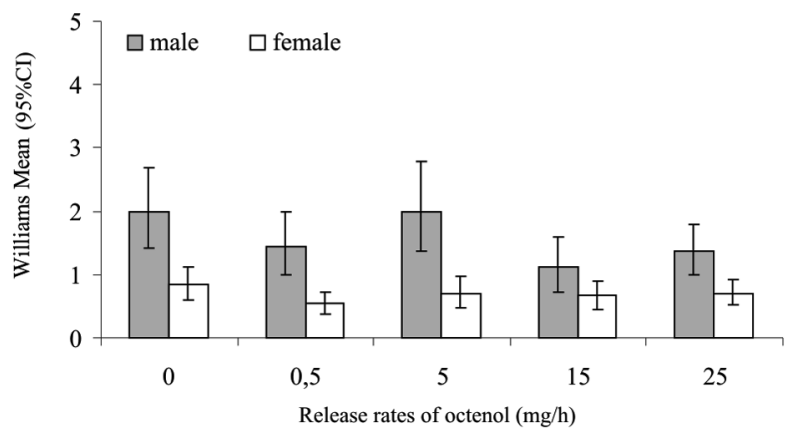

Fig. 3: Williams mean $(95 \% \mathrm{CI})$ of males and females of $L$. intermedia (A) and L. longipalpis (B) captured by light traps baited with different release rates octenol during five nights in Experiment 1 (Brejo do Mutambal, MG-April 2005).

was observed at higher release rates (Kruskal-Wallis, $\mathrm{p}=0.883)$ (Fig. 3). The greater percentage of $L$. longipalpis $(71.3 \%)$ catches were observed in the peridomiciliary area (Mann-Whitney, $\mathrm{p}=0.235$ ).

Evaluation of phlebotomine sand fly species' response to BGML kairomone baited in LT with or without octenol - Experiment 1 showed that LT baited with different release rates of octenol did not enhance the capture of phlebotomine sand flies of the genus Lutzomyia (Fig. 2). However, the $5 \mathrm{mg} / \mathrm{h}$ rate was chosen to be used in this experiment because it elicited a higher response than other release rates. A total of 871 phlebotomine sand flies were captured during this experiment; 452 females
(55\%) and 419 males (45\%). The number of $L$. intermedia males caught (72\%) was greater than females (28\%) in all traps (Mann-Whitney, $\mathrm{p}=0.1397$ ). The BGML used in the traps with a semi-open dispenser did not increase the capture of the phlebotomine sand fly species, especially for $L$. intermedia males (Kruskal-Wallis, $\mathrm{p}=0.756$ ) and females (Kruskal-Wallis, $\mathrm{p}=0.565$ ) (Fig. 4). Generally, the mean number of L. longipalpis males caught in all traps was significantly higher than females (Mann-Whitney, $\mathrm{p}<0.001$ ) (Fig. 4). However, no significant difference was observed in relation to the capture of males (Kruskal-Wallis, $p=0.920$ ) and females (KruskalWallis, $\mathrm{p}=0.970$ ) during the five days of collection.

Evaluation of phlebotomine sand fly species' response to BGML kairomones and the individual constituents of the formulation baited in LT - Based on the results from experiment 2 , the open dispenser was chosen for the evaluation of the BGML and the individual compounds (i.e., lactic acid, caproic acid, and ammonia) separately, and always in the absence of octenol. The 25 LT placed in the peridomiciliary area captured 476 phlebotomine sand flies during the five-night period. The total numbers of captured phlebotomine sand flies were $184,179,166$, and 152 in the traps baited with caproic acid, lactic acid, ammonia, and BGML, respectively. All the traps baited with attractants caught more individuals in comparison to the control trap (145) (KruskalWallis, $p=0.297)$. During this experiment, the population of $L$. intermedia was very low and did not present

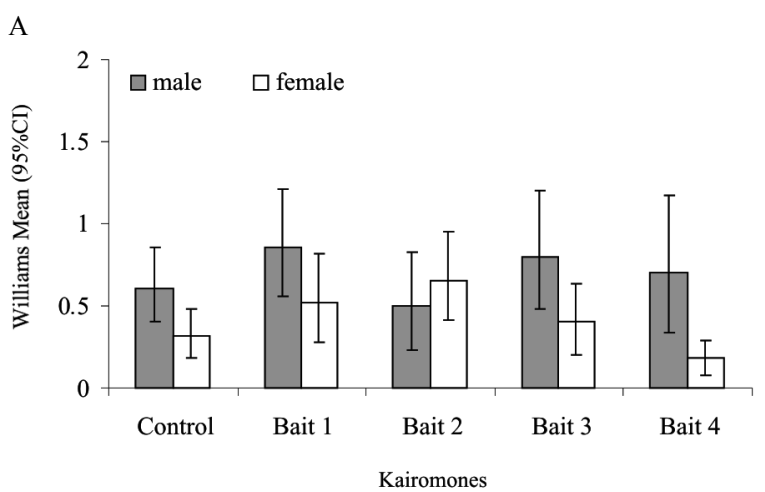

B

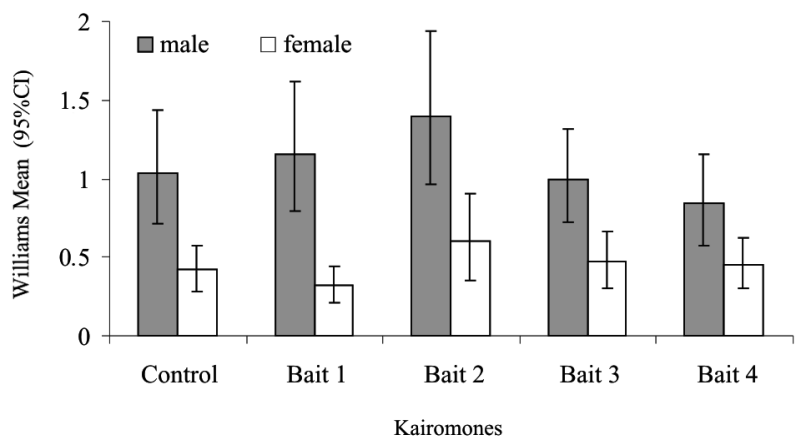

Fig. 4: Williams mean $(95 \% \mathrm{CI})$ of males and females of $L$. intermedia (A) and L. longipalpis (B) captured by light traps control (Control), with BGML open (Bait 1), BGML open+octenol 5mg/h (Bait 2), BGML semi-open (Bait 3), and BGML semi-open+octenol 5mg/h (Bait 4) during five nights in Experiment 2 (Brejo do Mutambal, MG-May 2005). 
any meaningful difference between the treatments for males (Kruskal-Wallis, $p=0.954$ ) or females (KruskalWallis, $p=0.314)($ Fig. 5). Females were captured only with traps baited with one of the compounds. The mean number of $L$. longipalpis males captured in all traps was significantly higher than females (Mann-Whitney, $\mathrm{p}<0.001)$. The LT baited with the BGML formulation captured a higher number of $L$. longipalpis when compared to individual kairomones and the control. However, there was no increasing lure regarding the mean number of males caught (Kruskal-Wallis, $p=0.512$ ) neither females (Kruskal-Wallis, $\mathrm{p}=0.737$ ).

A

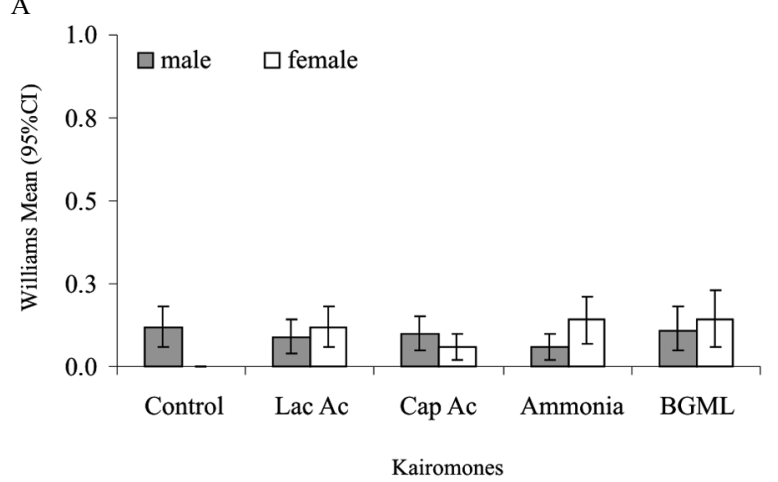

B

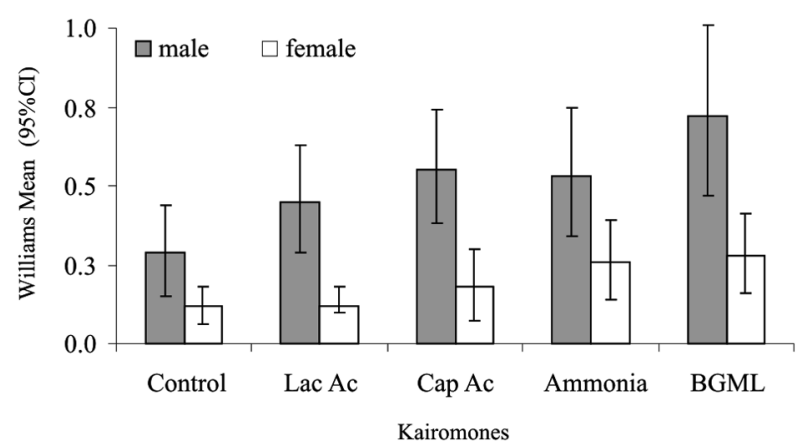

Fig. 5: Williams mean $(95 \% \mathrm{CI})$ of males and females of $L$. intermedia (A) and L. longipalpis (B) captured by light traps control and baited with lactic acid, caproic acid, ammonia and, BGML during five nights in Experiment 3 (Brejo do Mutambal, MG-May 2005).

\section{DISCUSSION}

The present study reports for the first time the response of $L$. intermedia and $L$. longipalpis to synthetic human odor and octenol. It is well-known that phlebotomine sand flies respond to LT, but the capture rate can increase when baited with host kairomones. Octenol is reported to be an important kairomone for finding hosts (Gibson \& Torr 1999) and it is also known as a constituent of human odor (Bernier et al. 2000). Using CDC LT, Cameron et al. (1991) did not find $(0.5 \mathrm{mg} / \mathrm{h})$ octenol to be attractive for Phlebotomus argentipes Annandale and Brunetti. In Egypt, CDC LT baited with octenol (about 15 and $100 \mathrm{mg} / \mathrm{h}$ ) showed that Phlebotomus papatasi (Scopoli) females are more attracted to traps baited with $\mathrm{CO}_{2}$ when compared to octenol alone at both rates (Beavers et al. 2004). In the laboratory, electrophysiological studies showed for the first time that females of L. longipalpis can detect octenol in air currents (Sant'Ana et al. 2002).

In experiment 1 of the present study, the number of L. intermedia females captured increased according to increasing release rates of octenol, whereas octenol did not enhance the capture of $L$. longipalpis. It is interesting that a higher number of males compared to females were observed, as occurred in previous studies (Aguiar et al 1996, Ximenes et al. 1999, Souza et al. 2002, Barata et al. 2004, Souza et al. 2004, Resende et al. 2006). The response to octenol seems to be species-specific, and it may act as an attractor to some species and as a repellent to others (Kemme et al. 1993). Nevertheless, it is not possible to assure the feasible repellent effects of octenol on these species in the present study. On the other hand, the presence of host kairomones in the traps does not inhibit the capture of both species, and it is likely to be attractive for $L$. intermedia.

Aggregation studies of $L$. longipalpis revealed that co-specific males arrive earlier to host bait and this attractiveness is likely to be elicited by host odors (Kelly \& Dye 1997). Spiegel et al. (2005) showed that L. longipalpis males from Jacobina (state of Bahia, Brazil) were attracted by the male sex pheromone (1S, 3S, 7R)3 -methyl- $\alpha$-himachalen alone within a wind tunnel, and it elicited electrophysiological responses on female and male antennae. It is possible that the male sex pheromones play an important role in male aggregation. It is unknown whether the male sex pheromone produced by L. longipalpis complex population in MG (Hamilton et al. 1999, 2004) acts in male aggregation as was previously demonstrated by Spiegel et al. (2005). It is possible that male attraction to LT (with or without baits) is higher than the female attraction. Hamilton and Ramsoondar (1994) demonstrated that $L$. longipalpis females respond more intensely to human odor emanation than males. In experiment 2 of the present study, a higher percentage of capture was observed for males in all traps baited with BGML; however, when baited without octenol, a decrease in the capture of L. longipalpis was observed. This suggests that octenol is not part of the human odor blend that acts as kairomones for this species.

Campbell-Lendrum et al. (1999b) suggested that $L$. intermedia is more endophagic than Lutzomyia whitmani (Antunes and Coutinho). This is probably due to a higher attraction to light stimuli for L. intermedia to enter human dwellings for blood meal. Maroli et al. (1997) reported that LT baited with attractants for phlebotomine sand flies are important for taxonomic studies as well as the capture of live specimens, study of density and distribution of species, and the evaluation of control traps. In the present study, BGML was not found to increase the capture of $L$. intermedia when compared to control traps. The formulation presented may not work as an attractant for this species or the release rate of the formulation was too high for attraction.

Among the kairomones used, the formulation of BGML for $L$. longipalpis presented a higher capture rate not only compared to the control traps but also to kairomones used separately. Laboratory studies showed that 
human sweating is an attractant for L. longipalpis in the absence of $\mathrm{CO}_{2}$ (Hamilton \& Ramssondar 1994, Rebollar-Tellez et al. 1999). This response was also observed in the present experiments for L. longipalpis in the traps baited with kairomones, especially with BGML.

Although light is an important stimulus to phlebotomine sand flies, some species are highly anthropophilic and present low phototropism (Alexander et al. 1995, Travi et al. 1998). Other species, like L. verrucarum, seem to be more phototropic than anthropophilic (Davies et al. 1995). It is likely that the attraction of some phlebotomine sand fly species to light sources in dark places is probably higher than host odor plumes and both may have synergic or additive effects on attraction to baited traps. Moreover, in the present study, adding attractants to the LT increased the capture rate of L. longipalpis and L. intermedia. In experiment 3 , we observed that only baited LT caught females of $L$. intermedia. This observation is important in an epidemiological view. This species has been suspected to be involved in the transmission of Leishmania braziliensis (Vianna) (Rangel \& Lainson 2003), and the baits can be used in LT to increase the capture of this species when the population density is low.

Although $\mathrm{CO}_{2}$ is the most important kairomone released by vertebrates and used by most haematophagous insects for host location (Eiras 2001), its use in the field is difficult and limited. Therefore, BGML can overwhelm as a possible attractant for phlebotomine sand flies. Future studies to evaluate the effectiveness of different concentrations and combinations of caproic acid and ammonia in attracting phlebotomine sand flies should be carried out. In conclusion, the present study reports for the first time the response of New World phlebotomine sand fly species to LT baited with octenol, caproic acid and ammonia under field conditions.

\section{ACKNOWLEDGEMENTS}

To Filipe Dantas-Torres, from CPqAM-Fiocruz, Brazil, for his invaluable comments on a draft of this manuscript and English revision, Dr. Owen Jones, from AgriSense BCS Ltd, Protypridd, UK, for providing octenol dispensers, and Dr. Martin Geier, from BioGents GmbH, Regensburg, Germany, for providing BG Mesh Lure ${ }^{\mathrm{TM}}$ kairomone formulation.

\section{REFERENCES}

Acree FJ, Turner RB, Gouck HK, Bezora M, Smith N 1968. L-Lactic acid: a mosquito attractant isolated from humans. Science 161: 1346-1347.

Afonso MMS, Gomes AC, Meneses CRV, Rangel EF 2005. Studies on the feeding habits of Lutzomyia (N.) intermedia (Diptera, Psychodidae), vector of cutaneous leishmaniasis in Brazil. Cad Saude Publica 21: 1816-1820.

Aguiar GM, Medeiros WM, Marco TS, Santos SC, Gambardella S 1996. Ecologia de flebotomíneos da Serra do Mar, Itaguaí, Estado do Rio de Janeiro, Brasil. I - A fauna flebotomínica e prevalência pelo local e tipo de captura. (Diptera, Psychodidae, Phlebotominae). Cad Saude Publica 12: 195-206.

Alexander B, Usma MC, Cadena H, Quesada BL, Solarte Y, Roa W, Travi BL 1995. Evaluation of deltamethrin-impreganated bednets and curtains against phlebotominae sandflies in Valle del Cauca, Colombia. Med Vet Entomol 9: 279-283.
Andrade AJ, Andrade MR, Barata RA, Pinto MC, Dias ES, Eiras AE 2007. Quatro novos registros da fauna flebotomínica do gênero Lutzomyia spp. França (Diptera: Psychodidae: Phlebotominae) do distrito rural de Brejo do Mutambal, Varzelândia (MG), Brasil. Neotrop Entomol 36: 980-983.

Barata RA, França-Silva JC, Fortes-Dias CL, Costa RT, Silva JC, Vieira EP, Prata A, Michalsky EM, Dias ES 2004. Phlebotomine sand flies in Porteirinha, an area of American visceral leishmaniasis in the State of Minas Gerais, Brazil. Mem Inst Oswaldo Cruz 99: 481-487.

Beavers GY, Hanafi AH, Dykstra EA 2004. Evaluation of 1-octen3-ol and carbon dioxide as attractants for Phlebotomus papatasi (Diptera: Psychodidae) in Southern Egypt. J Am Mosq Control Assoc 20: 30-133.

Bernier UR, Kline DL, Schreck CE, Barnard DR, Yost RA 2000. Chemical analysis of human skin emanations: comparison of volatiles from human that differ in attraction of Aedes aegypti (Diptera: Culicidae). J Am Mosq Control Assoc 18: 186-195.

Bongiorno G, Habluetzel A, Khoury C, Maroli M 2003. Host preferences of phlebotominae sand flies at a hypoendemic focus of canine leishmaniasis in central Italy. Acta Trop 88: 109-116.

Bosch JO, Geier M, Beckh J 2000. Contribution of fatty acids to olfactory host finding of female Aedes aegypti. Chem Senses 25: 223-230.

Cameron MM, Amerasinghe FP, Lane RP 1991. The field response of Sri Lankan sanflies e mosquitoes to synthetic cattle-derived attractants. Parassitol 33 (Suppl. 1): 119-126.

Campbell-Lendrum DH, Brandão-Filho SP, Ready PD, Davies CR 1999a. Host and/or site loyalty of Lutzomyia longipalpis (Diptera: Psychodidae) in Brazil. Med Vet Entomol 13: 209-211.

Campbell-Lendrum DH, Pinto MC, Davies CR 1999b. Lutzomyia intermedia (Lutz and Neiva, 1912) more endofagic than Lutzomyia whitmani (Antunes and Coutinho, 1939) because it is more attracted to light? Mem Inst Oswaldo Cruz 94: 21-22.

Chaniotis BN 1983. Improved trapping of phlebotominae sandflies in light traps supplement with dry ice in a Neotropical rainforest. J Med Entomol 20: 222-223.

Christensen HA, Arias JR, Vasquez AM, Freitas RA 1982. Hosts of sandfly vectors of Leishmania braziliensis guyanensis in the Central Amazon of Brazil. Am J Med Hyg 31: 239-242.

Davies CR, Lane RR, Villaseca P, Pyke S, Campos P, Llanos-Cuentas EA 1995. The relation between CDC light-trap and human-bait catches of endophagic sandflies (Diptera: Psychodidae) in the peruvian Andes. Med Vet Entomol 9: 241-248.

Dias ES, França-Silva JC, Silva JC, Monteiro EM, Paula KM, Gonçalves CM, Barata RA 2007. Flebotomíneos (Diptera: Psychodidae) de um foco de leishmaniose tegumentar no Estado de Minas Gerais. Rev Soc Bras Med Trop 40: 49-52.

Eiras AE 2001. Mediadores químicos entre hospedeiros e insetos de doenças médico-veterinárias. In: EF Vilela, TMC Della-Lúcia (eds.), Feromônios de insetos: biologia, química e emprego no manejo de pragas. Holos, Ribeirão Preto, p. 99-112.

Eiras AE, Jepson PC 1991. Host location by Aedes aegypti (Diptera: Culicidae): a wind tunnel study of chemical cues. Bull Entomol Res 81: 151-160.

Forattini OP 1973. Entomologia Médica. Psychodidae. Phlebotominae. Leishmanioses. Bartonelose. Vol. IV, Edgard Blucher, São Paulo, $658 \mathrm{p}$.

Galati EAB 2003. Classificação de Phlebotominae. In EF Rangel, R Lainson, Flebotomíneos do Brasil, Fiocruz, Rio de Janeiro, p. 23-51. 
Geier M, Bosh OJ, Boeckh J 1999. Ammonia as an attractive of host odour for the yellow fever mosquito, Aedes aegypti. Chem Senses 24: 647-653.

Gibson G, Torr SJ 1999. Visual and olafactory responses of haematophagous Diptera to host stimuli. Med Vet Entomol 13: 2-23.

Hamilton JG, Brazil RP, Maingon R 2004. A fourth chemotype of Lutzomyia longipalpis (Diptera: Psychodidae) from Jaíbas, Minas Gerais State, Brazil. J Med Entomol 41: 1021-1026.

Hamilton JGC, Ibbotson HC, Hooper AM, Mori K, Pickett JA, Sano S 1999. 9-methylgermacrene-B confirmed by synthesis as the sex pheromone of the sandfly Lutzomyia longipalpis from Lapinha, Brazil, and the absolute stereochemistry defined as $9 S$. Chem Commun 23: 2335-2336.

Hamilton JGC, Ramsoondar TMC 1994. Attraction of Lutzomyia longipalpis to human skin odours. Med Vet Entomol 8: 375-380.

Hribar LJ, Leprince DJ, Foil LD 1992. Ammonia as an attractant for adult Hybomitra lasiophtalama (Diptera: Tabanidae). J Med Entomol 29: 346-348.

Kelly DW, Dye C 1997. Pheromones, kairomones and the aggregation dynamics of the sandfly Lutzomyia longipalpis. Anim Behav 53: 721-731.

Kemme JA, Van Essen PHA, Ritchie SA, Kay BH 1993. Response of mosquitoes to carbon dioxide and 1-octen-3-ol in southeast Queensland, Australia. J Am Mosq Control Assoc 9: 431-435.

Kline DL, Takken W, Wood JR, Carlson DA 1990. Field studies on the potencial of butanone, carbon dioxide, honey extracts, 1- octen3-ol, L-lactic acid and phenols as attractant and control. Med Vet Entomol 4: 383-391.

Knudsen AB, Lewis DJ, Tesh RB, Rudnick A, Jeffrey J, Singh I 1979. Phlebotominae sand flies (Diptera: Psychodidae) from a primary hill forest in West Malaysia. J Med Entomol 15: 286-291.

Kröckel U, Rose A, Eiras AE, Geier M 2006. New tools for surveillance of adult Aedes aegypti: comparison of trap catches with human landing capturein an urban enviroment. J Am Mosq Control Assoc 22: 229-238.

Lainson R 1989. Demographic changes and their influence on the epidemiology of the American leishmaniasis. In MW Service (ed.) Demography of vector-borne diseases, Boca Raton, Florida, 416 pp.

Larson TV, Covert DS, Frank R 1979. A method for continuous measurement of ammonia in respiratory airways. J Appl Physiol 46: $603-607$.

Lemos JC, Lima SC 2005. Leishmaniose tegumentar americana: flebotomíneos em área de transmissão no Município de Uberlândia, MG. Rev Soc Bras Med Trop 38: 22-26.

Maroli M, Feliciangeli MD, Arias J 1997. Métodos de captura, conservacion y montaje de los flebotomos (Diptera: Psychodidae), OPS/OMS/HCP/HCT/95/97, Washington, 72 pp.

Nigam Y, Ward RD 1991. The effects of male sandfly pheromone and host factors as attractantas for female Lutzomyia longipalpis (Diptera: Psychodidae). Physiol Entomol 16: 305-312.

Nunes AG, Paula EV, Teodoro R, Prata A, Silva-Vergara ML 2006. Aspectos epidemiológicos da leishmaniose tegumentar americana em Varzelândia, Minas Gerais, Brasil. Cad Saude Publ 22: $1343-1347$.

Pinto MC, Campbell-Lendrum DH, Lozovei AL, Teodoro U, Davies CR 2001. Phlebotominae sandfly responses to carbon dioxide and human odour in the field. Med Vet Entomol 15: 132-139.
Pugedo H, Barata RA, França-Silva JC, Silva JC, Dias ES 2005. HP: um modelo aprimorado de armadilha luminosa de sucção para a captura de pequenos insetos. Rev Soc Bras Med Trop 38: 70-72.

Quinnell RJ, Dye C, Shaw JJ 1992. Host preferences of the phlebotominae sandfly Lutzomyia longipalpis in Amazonian Brazil. Med Vet Entomol 6: 195-200.

Rangel EF, Lainson, R 2003. Transmissores de leishmaniose tegumentar americana. In EF Rangel, R Lainson, Flebotomíneos do Brasil, Rio de Janeiro, Fiocruz, p. 291-309.

Rebollar-Tellez EA, Hamilton JGC, Ward RD 1999. Responses of female Lutzomyia longipalpis to host odour kairomones from human skin. Physiol Entomol 24: 220-226.

Resende MC, Camargo MCV, Vieira JRM, Nobi RCA, Porto NMN, Oliveira CDL, Pessanha JE, Cunha MCM, Brandão ST 2006. Seasonal variation of Lutzomyia longipalpis in Belo Horizonte, state of Minas Gerais. Rev Soc Bras Med Trop 39: 51-55.

Sant'Ana AL, Eiras AE, Cavalcante RR 2002. Electroantennographic responses of the Lutzomyia (Lutzomyia) longipalpis (Lutz \& Neiva) (Diptera: Psychodidae) to 1-octen-3-ol. Neotrop Entomol 31: 13-17.

Shannon R 1939. Methods for collecting and feeding mosquitos in jungle yellow fever studies. Amer J Trop Med Hyg 19: 131-148.

Souza CM, Pessanha JE, Barata RA, Monteiro EM, Costa DC, Dias ES 2004. Study on phlebotominae sand fly (Diptera: Psychodidae) fauna in Belo Horizonte, state of Minas Gerais, Brazil. Mem Inst Oswaldo Cruz 99: 795-803.

Souza NA, Andrade-Coelho CA, Vilela ML, Peixoto AA, Rangel EF 2002. Seasonality of Lutzomyia intermedia and Lutzomyia whitmani (Diptera: Psychodidae: Phlebotominae), occurring sympatrically in area of cutneous leishmaniasis in the state of Rio de Janeiro, Brazil. Mem Inst Oswaldo Cruz 97: 759-765.

Spiegel CN, Jeanbourquin P, Guerin PM, Hooper AM, Claude S, Tabacchi R, Sano S, Mori K 2005. (1S, 3S, 7R)-3-methyl- $\alpha$ himachalene from the male sandfly Lutzomyia longipalpis (Diptera: Psychodidae) induces neurophysiological responses and attracts both males and females. J Insect Physiol 12: 1-10.

Sudia WA, Chamberlain RW 1962. Battery-operated light trap: an improved model. Mosq News 22: 126-129.

Travi BL, Montoya, Solarte Y, Lozano L, Jaramilha C 1998. Leishmaniasis in Colombia. I. Studies on the phlebotominae fauna associated with endemic foci in the Pacific Coast region. Am J Trop Med Hyg 39: 261-266.

Van Essen PHA, Kemme JA, Ritchie SA, Kay BH 1994. Differential responses of Aedes and Culex mosquitoes to octenol or light in combination with carbon dioxide in Queensland, Australia. Med Vet Entomol 8: 63-67.

Williams CB 1937. The use of logarithms in the interpretation of certain entomological problems. Ann Appl Biol 24: 404-414.

Ximenes MFFM, Souza MF, Castellón EG 1999. Density of sand flies (Diptera: Psychodidae) in domestic and wild animal shelters in an area of Visceral. Leishmaniasis in State of Rio Grande do Norte, Brazil. Mem Inst Oswaldo Cruz 94: 427-432.

Young DG, Duncan MA 1994. Guide to the Identification and Geographic distribution of Lutzomyia sand flies in Mexico, the West Indies, Central and South America (Diptera: Psychodidae), American Entomological Institute, Associated Publishers, Gainesville, 419 pp. 